\title{
Reevaluation of the Turn-of-the-Century Seismicity Peak
}

\author{
Hiroo KanAmori AND KaTSUYUKI ABE' \\ Seismological Laboratory, California Institute of Technology, Pasadena, California 91125
}

\begin{abstract}
According to currently available seismicity catalogues, seismicity (for example, the number of events with $M_{s} \geq 8$ ) around the turn of the century, from 1897 to 1906 , was significantly higher than in recent years. However, the magnitudes of the earthquakes which occurred during this period were determined by Gutenberg, who used the records obtained by the undamped Milne seismograph with the assumption that the effective magnification is 5 . Because of saturation of the Milne seismogram for very large events used by Gutenberg for calibration, the gain $(=5)$ used by Gutenberg could have been underestimated, and therefore the magnitude overestimated. Because of the lack of damping, the magnification of this instrument needs to be calibrated carefully. In order to calibrate the instrument response, a Milne seismograph was constructed and has been in operation side by side with damped seismographs at Pasadena. Eleven events have been recorded since February 1977. On the basis of (1) comparison of the amplitudes measured on the Milne seismograms with those of the standard seismograms, (2) numerical experiments simulating the response of the Milne seismographs to surface waves, and (3) examination of Gutenberg's original materials used for the calibration, we conclude that the average effective gain is as large as 20 for very large earthquakes, resulting in systematic reduction of the magnitude of up to 0.6. This reduction is large enough to suggest that the turn-of-the-century seismicity peak is of marginal significance.
\end{abstract}

\section{INTRODUCTION}

According to currently available seismicity catalogues [e.g., Gutenberg, 1956a; Richter, 1958] the number of earthquakes larger than $M_{s}$ (surface wave magnitude) $=8$ was significantly larger around the turn of the century, from 1897 to 1906, than in recent years (Figure 1). The data used in Figure 1 for the period from 1897 to 1903 are taken from Richter [1958], who converted the magnitudes, $m$, determined by Gutenberg [1956a] to the values corresponding to the surface wave magnitude, $M_{s}$. For the period 1904 to 1952 we used the surface wave magnitude $M_{s}$ listed by Geller and Kanamori [1977]. Except for a few events the values of $M_{s}$ of Geller and Kanamori are essentially the same as the magnitudes listed by Gutenberg and Richter [1954]. For the period 1953 to 1977 the surface wave magnitude determined by Abe and Kanamori [1979] is used. Thus the magnitude scale used in Figure 1 is considered to be uniform throughout the entire period.

As was demonstrated by several recent studies [e.g., Kanamori, 1977], the surface wave magnitude $M_{s}$ saturates for very large earthquakes. Therefore the increase in the number of earthquakes with a large $\boldsymbol{M}_{\boldsymbol{s}}$ does not necessarily indicate an increase in the total energy released by earthquakes. Nevertheless, this peak in the number of large events is so remarkable that it has attracted considerable interest of geophysicists in the past.

Gutenberg [1956a] argued that the average annual energy release during the period 1896 to 1906 is about 3 times larger than that for the period from 1907 to 1955 . Unfortunately, most seismographs operated prior to 1904 were without a damping device, so the magnitude determination was inevitably unreliable. Gutenberg [1956a] made an extensive investigation into this problem by using records obtained by undamped Milne seismographs (see, for example, Reid [1912] for the Milne seismograph; examples of the seismograms written by the Milne seismograph are given by Richter [1958, p. 272] and Walker [1913, Plates 8 and 9]).

\footnotetext{
' Now at Department of Geophysics, Faculty of Science, Hokkaido University, Sapporo, Japan 060.

Copyright $(9) 1979$ by the American Geophysical Union.
}

The purpose of the present study is to reevaluate this peak by constructing and operating an undamped Milne seismograph at Pasadena. Fortunately, Gutenberg's original work sheets used for the 1956 paper were found in the archives of Millikan Memorial Library, California Institute of Technology. This material is extremely useful for the present study. By using this material we first follow Gutenberg's procedure.

\section{GUTENBERG'S STUdY}

In order to determine the magnitude the gain of the seismograph must be known. The Milne seismograph that Gutenberg [1956a] used is an undamped system, and its effective magnification for transient seismic waves is not known very well. $G u$ tenberg [1956a] calibrated this instrument by using 16 large earthquakes which occurred during the period from 1904 to 1907. For these events both Milne seismograms and the seismograms recorded by more advanced damped instruments were available. The surface wave magnitude $M_{s}$ of these events had been determined from the amplitude data obtained by the damped seismographs. In these determinations, Gutenberg's [1945] method was employed. Gutenberg used the amplitude of surface waves having periods of about $20 \mathrm{~s}$ and determined $M_{s}$ using the amplitude-distance function given by Gutenberg [1945, Table 3].

Gutenberg's [1956a] method of calibration is as follows: he first used the maximum trace amplitude $A_{t}$ (half the peak-topeak amplitude) on the Milne seismograms reported in the publications of the British Association for the Advancement of Science (for references, see Gutenberg [1956a]). Then he calculated the magnitude $M_{s}^{*}$ by

$$
M_{s}^{*}=\log \left(A_{t} / G\right)+Q(\Delta)+s
$$

where $Q(\Delta)$ is the $Q$ function listed by Gutenberg [1945] (i.e., $Q=1.656 \log \Delta+1.818$ ), $s$ is the station correction (listed by Gutenberg [1956a]), and $G$ is the effective gain of the seismograph. The $Q$ function used here is identical to that used for the $M_{s}$ determination. Gutenberg [1956a] adjusted $G$ to make $M_{s}^{*}$ equal to $M_{s}$. He found that $G=5$ is most satisfactory. Actually, Gutenberg [1956a] made all the calculations by using the magnitude scale on the body wave basis, $m$, instead of $M_{s}$. Since $M_{s}$ and $m$ are numerically related by $M_{s}=1.59 m-4.0$ 


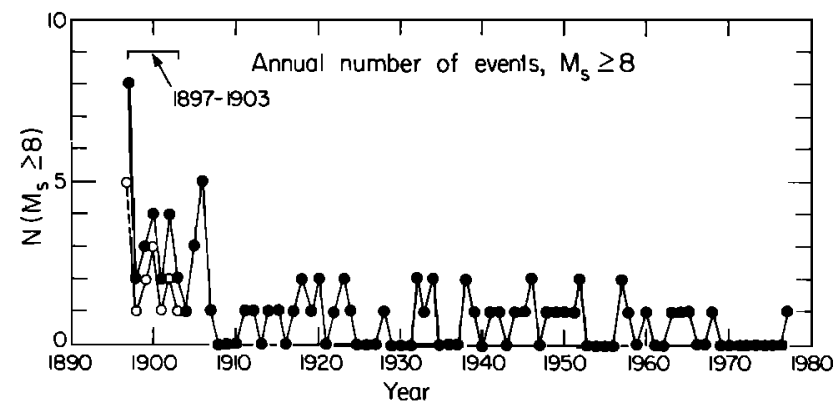

Fig. 1. Annual number of earthquakes larger than $\boldsymbol{M}_{s}=8$. Solid circles show the results obtained from currently available catalogues (for 1897-1903: Richter [1958]; for 1904-1952: Gutenberg and Richter [1954] and Geller and Kanamori [1977]; and for 1953-1977: Abe and Kanamori [1979]). Open circles for the period 1897-1903 indicate the revised values obtained by the present study.

[Gutenberg, 1956a, $b$ ], there is no fundamental difference whether $m$ or $M_{s}$ is used. An illustrative example for the 1906 San Francisco earthquake is given by Gutenberg [1956a]. The values of $m$ and $M_{s}$ for these 16 events are listed by Gutenberg [1956a] and Richter [1958], respectively.

TABLE 1. $M_{s}^{*}$ of the Ecuador Earthquake of January 31, 1906, and the San Francisco Earthquake of April 18, 1906

\begin{tabular}{|c|c|c|c|}
\hline Station & $\begin{array}{c}\Delta, \\
\operatorname{deg}\end{array}$ & $\begin{array}{c}A, \\
\mu \mathrm{m}\end{array}$ & $M_{s}^{*}$ \\
\hline \multicolumn{4}{|c|}{ Ecuador, $M_{s}=8.7$} \\
\hline Shide & 83 & $>4000$ & $>8.6$ \\
\hline Kew & 82 & $>3400$ & $>8.5$ \\
\hline San Fernando & 80 & $>3500$ & $>8.5$ \\
\hline Capetown & 99 & 1000 & 8.1 \\
\hline Azores & 56 & 1600 & 7.9 \\
\hline Toronto & 43 & $>4000$ & $>8.1$ \\
\hline Victoria & 59 & 3200 & 8.3 \\
\hline Alicante & 155 & $>4000$ & $>9.0$ \\
\hline Bombay & 150 & 3040 & 8.9 \\
\hline Kodaikanal & 156 & $>4400$ & $>9.1$ \\
\hline Beirut & 112 & 2000 & 8.5 \\
\hline Baltimore & 39 & $>3200$ & $>8.0$ \\
\hline Irkutsk & 126 & $>3400$ & $>8.8$ \\
\hline Honolulu & 79 & $>8000$ & $>8.9$ \\
\hline Tokyo & 127 & 1700 & 8.5 \\
\hline Christchurch & 102 & 3100 & 8.6 \\
\hline Colombo & 160 & 2800 & 8.9 \\
\hline Average & & & 8.5 \\
\hline \multicolumn{4}{|c|}{ San Francisco, $M_{s}=8.3$} \\
\hline Shide & 77 & 4000 & 8.5 \\
\hline Azores & 73 & 1460 & 8.1 \\
\hline Calcutta & 113 & 3400 & 8.7 \\
\hline Bombay & 121 & 1260 & 8.4 \\
\hline Kodaikanal & 128 & 500 & 8.0 \\
\hline Batavia & 125 & 600 & 8.1 \\
\hline Helwan & 108 & 900 & 8.1 \\
\hline Trinidad & 61 & 2000 & 8.1 \\
\hline Perth & 132 & 550 & 8.1 \\
\hline Wellington & 95 & 1800 & 8.3 \\
\hline Tokyo & 73 & 900 & 7.9 \\
\hline Christchurch & 100 & 1360 & 8.3 \\
\hline Colombo & 120 & 1500 & 8.4 \\
\hline Mauritius & 162 & 1000 & 8.5 \\
\hline Kew & 75 & $>3400$ & $>8.5$ \\
\hline Edinburgh & 73 & $>3400$ & $>8.4$ \\
\hline Paisley & 75 & $>3400$ & $>8.5$ \\
\hline San Fernando & 85 & $>3500$ & $>8.6$ \\
\hline Toronto & 33 & $>4000$ & $>7.9$ \\
\hline Irkutsk & 81 & $>3400$ & $>8.5$ \\
\hline Average & & & 8.3 \\
\hline
\end{tabular}

$\Delta$ is the distance, and $A$ is the amplitude of the ground motion, in microns, calculated from the maximum trace amplitude on the Milne seismograms with the assumption that the magnification is 5 .

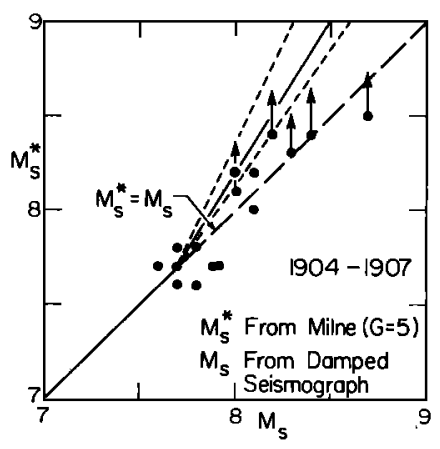

Fig. 2. Relation between $M_{s}^{*}$ (the surface wave magnitude determined from the Milne seismograms with the assumption that the gain is 5) and $\boldsymbol{M}_{s}$ (the surface wave magnitude determined from the records of damped seismographs). Arrows indicate saturated cases. The solid line indicates the relation between $M_{s}^{*}$ and $M_{s}$ suggested by the present study. The dotted lines indicate the relations obtained with different assumptions.

We first repeated Gutenberg's [1956a] procedure by using $M_{s}$. Table I shows two examples, one for the 1906 Ecuador earthquake $\left(M_{s}=8.7\right)$ and the other for the 1906 San Francisco earthquake $\left(M_{s}=8.3\right)$. The results for the remaining 14 events are shown in Table A-3 (see also Table A-2) in the appendix.' The amplitude $A$ in these tables refers to the maximum ground displacement, in microns, calculated with the assumption that $G=5$. Figure 2 compares $M_{s}$ and $M_{s}^{*}$ for the 16 events. As Gutenberg [1956a] noted, $M_{s}^{*}$ seems to agree very well with $\boldsymbol{M}_{\boldsymbol{s}}$. However, during the course of this comparison we noticed a rather serious problem. As indicated in Table 1, many seismograms used for the calibration were off scale. In these cases, Gutenberg [1956a] used the values where the saturation occurred. Since most Milne seismographs used recording papers about $35 \mathrm{~mm}$ wide, saturation must have occurred at $M_{s}=8.6,8.3$, and 8.1 at a distance of $\Delta=90^{\circ}$, if $G=$ 5,10 , and 15, respectively. As shown in Table A-3 in the microfiche appendix, the saturation occurred for five out of eight events larger than $M_{s}=8$. In Figure 2 the saturated case is in dicated by an upward arrow attached to the data point. Saturation could cause underestimation of $M_{s}^{*}$, which in turn would result in underestimation of the effective gain $G$.

For earthquakes smaller than $M_{s}=7.7$ the agreement between $M_{s}^{*}$ and $M_{s}$ seems very good. Thus the effective gain appears to depend on $M_{s}$.

\section{MiLNe SEISMOgRAPH}

In order to investigate the calibration problem of the undamped Milne seismograph, we decided to operate a Milne seismograph side by side with the standard damped seismograph systems at the Seismological Laboratory of the California Institute of Technology. To the authors' knowledge, at least two original Milne seismographs still exist, one at the Science Museum in London and the other at the National Science Museum in Tokyo. However, both of these are on exhibit now and are not in operational condition. We therefore decided to build one following the original manufacturer's manual [Munro, 1908] kindly made available to us by A. McConnell of the Science Museum, London. We also referred to Reid [1912] and a detailed description kindly provided by T. Usami

\footnotetext{
' Tables are available with entire article on microfiche. Order from American Geophysical Union, 2000 Florida Avenue, N. W., Washington, D. C. 20009. Document J79-006; $\$ 01.00$. Payment must accompany order.
} 


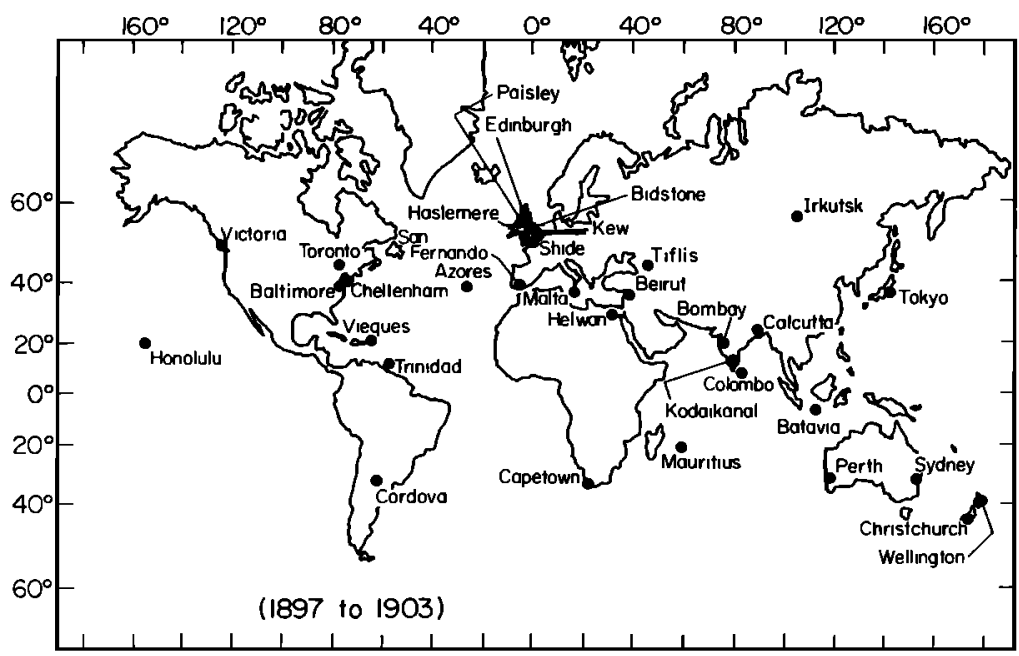

Fig. 3. Stations which operated the Milne seismograph during the period from 1897 to 1903.

of the University of Tokyo. In the construction the original seismograph was copied as closely as possible, except for the recording drum. We used a larger recording drum to obtain higher time resolution. It is unlikely that this modification affects the overall response of the instrument. Hereafter, we will call this newly built Milne seismograph the Pasadena Milne seismograph. The natural period and the static magnification of this instrument are $15 \mathrm{~s}$ and 4.5, respectively.

The details of the Milne seismograph are described by Reid [1912]. The instrument constants of the Milne seismographs which were in operation at various stations in the world around the turn of the century are listed in various issues of the Bulletin of the British Association for the Advancement of Science. These constants are summarized in Table A-1 in the microfiche appendix. The average natural period $T_{0}$ is $17.5 \mathrm{~s}$, and the static magnification $V$ is 6.0 . Figure 3 shows the distribution of the stations. In total, about 35 stations were in operation. Although not all of these stations were operational during the entire period from 1897 to 1903 , the station coverage was reasonably good toward the end of this period. Thus if calibration of the instrument could be made properly, a reasonably good estimate of the magnitude may be expected.

The difficulty of the calibration of undamped instruments is well known. As shown by Figure 4, the magnification becomes very large at the resonant period $(T=17.5 \mathrm{~s})$. In the

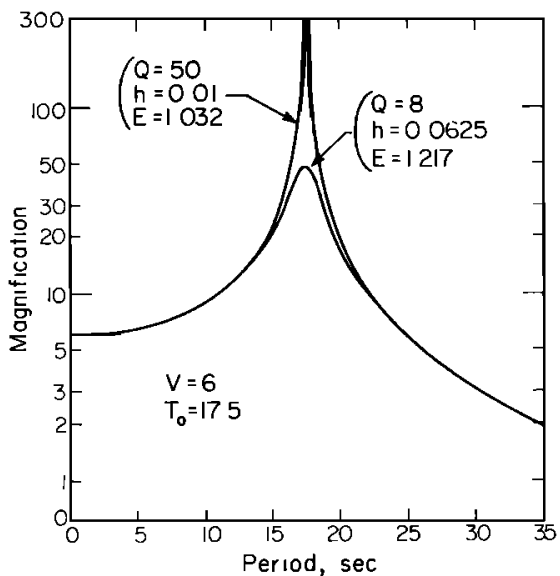

Fig. 4. Static magnification curve for the Milne seismograph. Note that the gain is substantially higher than 5 (value assumed by Gutenberg) in the period range from 10 to $23 \mathrm{~s}$. figure, two curves are shown for two cases with different damping. In the figure, $h$ is the damping constant, $E=\exp$ $\left[\pi h /\left(1-h^{2}\right)^{1 / 2}\right]$ is the damping ratio, and $Q=1 / 2 h$ is the quality factor. Since the magnification changes very rapidly as a function of period, the effective magnification of this system for a transient input signal depends upon various factors, such as the period, the wave form, the duration of the signal, the complexity, and the dispersion characteristics. Since the wave form of earthquake surface waves depends very strongly on the nature of the path (oceanic or continental), the epicentral distance, the magnitude of the event, and the depth of the events, the effective magnification of the undamped seismogram must strongly depend on these factors too. Therefore calibration must be made by recording various earthquakes by both the Milne seismograph and a damped seismograph with known characteristics.

Another uncertain element is the actual damping constant of the Milne seismograph. Although the Milne seismograph has no special damping mechanism, slight damping is caused either by solid friction at the pivot and/or viscous friction due to air. Unfortunately, the damping characteristics of the original Milne seismographs are not described in the literature in detail. According to Walker [1913, p. 22] the damping constant $h$ is 0.0257 ( $E=1.084, Q=19.5)$, and Knott [1908, p. 81] noted that the Milne seismograph at Edinburgh had $h=$ $0.0683(E=1.24, Q=7.32)$. Our Pasadena Milne seismograph, when it was initially built, had very little damping, $h=$ 0.014 ( $E=1.05, Q=35$ ). In order to increase the damping to that described by Walker [1913] and Knott [1908], we had to add a very weak magnetic damper to the seismograph boom. The damping constant of the Pasadena Milne seismograph with the magnetic damper is $h=0.05(E=1.17, Q=10)$. If the damping of the original instrument was mainly due to solid friction at the pivot, damping characteristics cannot be described by the damping constant $h$. In this case, $h$ should be considered the effective damping constant that approximates the actual damping characteristics. The reason why the Pasadena Milne seismograph without a damper had much smaller damping than the original instrument is not clear. One possibility is that the Pasadena Milne seismograph has a pivot made of hardened steel and sapphire, while the original instrument probably had a pivot made of hard metals.

In any case, if $h$ is smaller than 0.1, the magnification is significantly larger than the static magnification over a period 
TABLE 2. Comparison of the Magnitude Determination by Using the Pasadena Milne Seismograph and the Standard Seismographs

\begin{tabular}{|c|c|c|c|c|c|c|}
\hline Event & Date & Epicenter & $\begin{array}{c}\Delta, \\
\text { deg }\end{array}$ & $\begin{array}{c}M_{s} \\
\text { (Pasadena) }\end{array}$ & $M_{s, 1^{*}}$ & $\boldsymbol{G}$ \\
\hline 1 & Aug. 19, 1977 & Indonesia & 120 & 8.0 & 8.8 & 7.94 \\
\hline 2 & Feb. 19, 1977 & Aleutian Islands & 53 & 6.6 & 7.5 & 10.0 \\
\hline 3 & Sept. 4, 1977 & Aleutian Islands & 50 & 6.1 & 7.7 & 50.1 \\
\hline 4 & Sept. 4, 1977 & Aleutian Islands & 50 & 6.4 & 7.7 & 25.1 \\
\hline 5 & Aug. 31, 1977 & Colombia & 46 & 6.3 & 7.4 & 15.8 \\
\hline 6 & Sept. 4, 1977 & New Hebrides Islands & 85 & 6.2 & 7.3 & 15.8 \\
\hline 7 & Nov. 23, 1977 & Argentina & 82 & 7.0 & 8.6 & 50.1 \\
\hline 8 & March 24, 1978 & Kurile Islands & 67 & 7.2 & 8.2 & 12.6 \\
\hline 9 & Feb. 9, 1978 & Kermadec Islands & 83 & 7.2 & 8.2 & 12.6 \\
\hline 10 & June 12,1978 & Japan & 75 & 7.5 & 8.1 & 5.01 \\
\hline 11 & June 17,1978 & Tonga Islands & 72 & 7.2 & 8.2 & 12.6 \\
\hline
\end{tabular}

$G$ is the effective gain of the Milne seismograph determined for the individual event.

range shorter than $25 \mathrm{~s}$, as shown in Figure 4. Since the average static magnification is 6 , it is difficult to understand why Gutenberg obtained an effective gain as low as 5.

As will be shown later, the damping has a very large effect on the effective magnification. When $h$ was increased from $h$ $=0.016(E=1.05, Q=32)$ to $h=0.058(E=1.2, Q=8.6)$, the effective gain was reduced by approximately a factor of 2 . Since installation of the Pasadena Milne seismograph was completed we have recorded 11 large events listed in Table 2. An example is shown in Figure 5. In the table the maximum trace amplitudes on the Pasadena Milne seismogram $A_{f}$ and the surface wave magnitudes $M_{s}$ determined at Pasadena are listed. Following Gutenberg [1956a], the determination of the effective gain $G$ was made as follows.

The surface wave magnitude $M_{s}$ can be written as

$$
M_{s}=\log \left(A_{t} / G\right)+Q(\Delta)=M_{s, t}^{*}-\log G
$$

where

$$
M_{s, t}^{*}=\log A_{t}+Q(\Delta)
$$

Here $Q(\Delta)$ is the $Q$ function determined by Gutenberg [1945]. $M_{s, t} *$ defined by (3) can be calculated directly from the record and can be regarded as the magnitude when the effective gain is assumed to be unity. The values of $M_{s, i}^{*}$ are listed in Table 2. In order to adjust the difference between the average static magnification of the Milne seismographs which were in use around the turn of the century $(\times 6.0)$ and that of the Pasadena Milne seismograph (×4.5), the values of $A_{t}$ in Table 2 were multiplied by $6 / 4.5$ in the calculation of $M_{s, r^{*}}$

The values of $M_{s, t} *$ and $M_{S}$ are plotted in Figure 6. The solid lines show the trend for different values of $G$. From this figure the value of $G$ can be determined for each event. Although the value of $G$ varies over a very wide range, $G$ is larger than 5 in all cases. The average of $G$ is 19.8 .

Unfortunately, because of the geographical location of Pasadena with respect to the distribution of large earthquakes

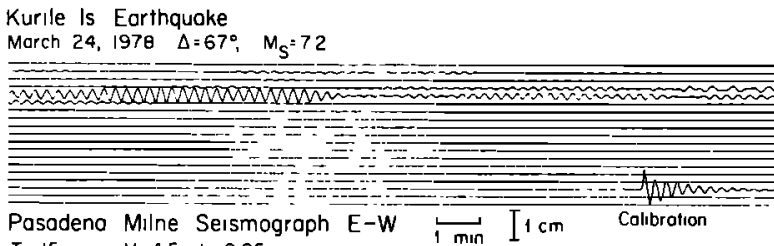

$T_{0}=15$ sec, $V=45, h=005$

Fig. 5. A surface wave train from an earthquake in the Kurile Islands recorded by the Pasadena Milne seismograph. Note the damping characteristic indicated by 'calibration.' in the world and of the recent decline in the activity of large earthquakes [Abe and Kanamori, 1979], the data shown in Table 2 are inevitably biased toward oceanic paths and smallmagnitude events. In order to supplement the data we made numerical experiments by using the surface wave signals recorded at Pasadena.

\section{NUMERICAL EXPERIMENTS}

In order to investigate the overall response of the Milne seismograph we calculated synthetic seismograms which would be recorded by the Milne seismograph by using the observed surface wave ground motion as the input. We chose 10 large events listed in Table 3 . We used surface wave records obtained by a vertical component of short-period Benioff seismograph (pendulum period, $1 \mathrm{~s}$; galvanometer period, 0.2 s) and deconvolved them by using the instrument response to obtain ground motions. Then we convolved them with the instrument response of the Milne seismograph to obtain synthetic seismograms. We assumed that the amplitude of the horizontal component is $70 \%$ of that of the vertical component. As shown in Figure 7, the amplitude of the synthetic seismograms depends on the damping of the instrument. We chose the instrument constants to be the same as the average values given in Table A-1 (i.e., $T_{0}=17.5 \mathrm{~s}, V=6.0$ ) and assumed that $h=0.058$. Then we measured $A_{1}$ and calculated $M_{s . l}{ }^{*}$. Two examples are shown in Figure 8. Figures 7 and 8

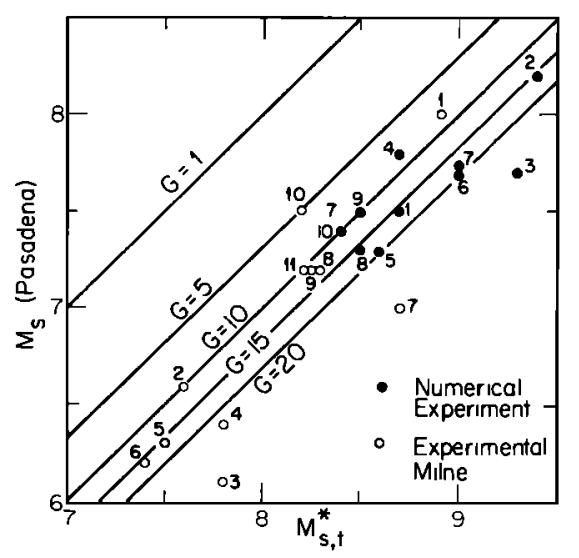

Fig. 6. Relation between $M_{s}$ (Pasadena) and $M_{s, t^{*}}$ (surface wave magnitude determined from the Milne seismograms with the assumption that the gain is equal to 1 . Solid lines indicate the relations for various values of $G$ (gain). Solid circles are the results obtained by the numerical experiments, and open circles are the results obtained with the Pasadena Milne seismograph. 
TABLE 3. Results of Numerical Experiment to Simulate the Response of the Milne Seismograph

\begin{tabular}{|c|c|c|c|c|c|c|}
\hline Event & Date & Epicenter & $\begin{array}{c}\Delta, \\
\text { deg }\end{array}$ & $\begin{array}{c}M_{s} \\
\text { (Pasadena) }\end{array}$ & $M_{s, i}$ & $\boldsymbol{G}$ \\
\hline 1 & Dec. 2,1972 & Mindanao Islands & 105 & 7.5 & 8.7 & 15.8 \\
\hline 2 & May 26,1975 & North Atlantic & 80 & 8.1 & 9.4 & 20.0 \\
\hline 3 & May 10,1975 & Chile & 82 & 7.8 & 9.3 & 31.6 \\
\hline 4 & July 20, 1975 & Solomon Islands & 90 & 7.8 & 8.7 & 7.9 \\
\hline 5 & Dec. 28,1973 & New Hebrides Islands & 89 & 7.0 & 8.6 & 39.8 \\
\hline 6 & Aug. 16, 1976 & Mindanao Islands & 108 & 7.7 & 9.0 & 20.0 \\
\hline 7 & June 17,1973 & Japan & 72 & 7.7 & 9.0 & 20.0 \\
\hline 8 & Jan. 10, 1974 & New Hebrides Islands & 88 & 7.0 & 8.5 & 31.6 \\
\hline 9 & Oct. 3,1974 & Peru & 62 & 7.5 & 8.5 & 10.0 \\
\hline 10 & Dec. 15,1971 & Kamchatka & 59 & 7.3 & 8.4 & 12.6 \\
\hline
\end{tabular}

illustrate the difficulties of using undamped instruments for the amplitude measurement. For a prolonged wave train caused by dispersion along oceanic paths (Solomon Island, Figure $7 a$; and New Hebrides, Figure $8 a$ ) the amplitude of the synthetic seismograms becomes very large owing to resonance. However, for wave trains with relatively short duration (for example, central Chile, Figure $8 b$ ) the growth of the amplitude is relatively modest. Thus it is not surprising that the effective gain varies very much according to the path.

The values of $M_{s, r}{ }^{*}$ and $M_{s}$ determined at Pasadena with damped seismographs are plotted in Figure 6. Again, the effective magnification is larger than 5 in all cases. The average of the effective gain $G$ is 20.9 .

\section{The Effective Gain of The Milne Seismograph}

As shown by Figure 6, the results obtained by both the Pasadena Milne seismograph experiment and the numerical experiment suggest that the effective gain is significantly larger than 5 , probably about 20 . This result suggests that saturation of the Milne seismograms for very large earthquakes caused underestimation of the effective magnification (Figure 2). If the gain is $\mathbf{2 0}$ instead of 5 , it would cause an error in the magnitude of 0.6 , which is very significant.

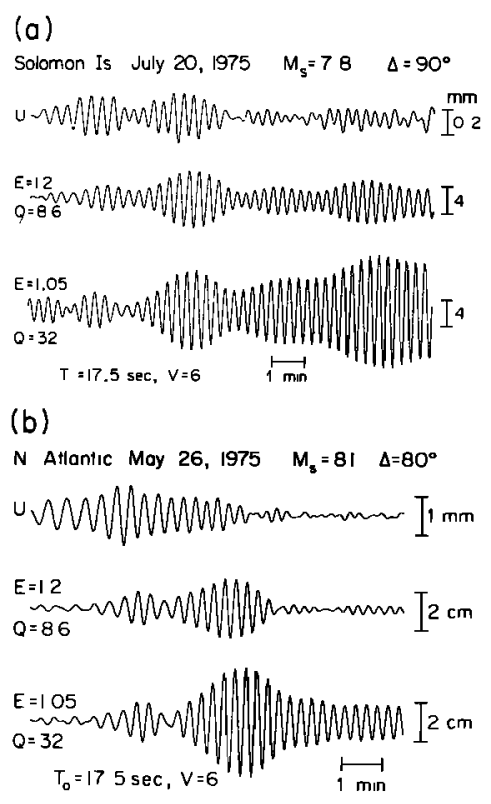

Fig. 7. Surface wave ground motions $(U)$ and the response of the Milne seismograph computed for two damping constants. $(a)$ Solomon Islands earthquake of July 20, 1975. (b) North Atlantic earthquake of May 26, 1975.
However, the following two problems need be considered further. First, Gutenberg [1956a] obtained a good agreement between $M_{s}^{*}$ and $M_{s}$ for smaller earthquakes under the assumption that $G=5$. Second, the damping of the original instrument appears significantly larger than that of the Pasadena Milne seismograph (without a magnetic damper), suggesting that the damping of the original instrument is partially due to solid friction at the pivot.

As is well known [e.g., Cloud and Hudson, 1961], the effect of solid friction is more pronounced when the amplitude is very small. Once the amplitude exceeds a certain threshold, motion of the pendulum overcomes solid friction. Thus one possibility is that for relatively small magnitude $\left(M_{s} \leq 7.7\right)$ events, the amplitude of the pendulum motion is not large enough to overcome solid friction completely, resulting in a relatively small effective magnification. On the other hand, when the magnitude is large, the effect of solid friction becomes relatively unimportant, and the effective magnification increases.

With these considerations we estimated the effective gain in the following manner. Our basic philosophy is that inasmuch as Gutenberg used a very-large number of Milne records for calibration, we use Gutenberg's [1956a] results as much as possible with only modification to remove the effect of saturation. We thus assumed that the effective gain $G$ is 5 for $M_{s} \leq 7.7$ (see Figure 2) but gradually increases to 20 until $M_{s}=8.7$ (the magnitude of the largest event used for calibration) is reached. For $M_{s} \geq 8.7, G$ is set equal to 20 . Although there is no compelling reason why the maximum gain $G=20$ should be reached at $M_{s}=8.7$, it is probably reasonable to assume that the transition from friction-controlled state to friction-free

(a)

$$
\begin{aligned}
& \text { New Hebrides Dec 28, } 1973 \quad M_{\mathrm{s}}=70 \quad \Delta=89^{\circ}
\end{aligned}
$$

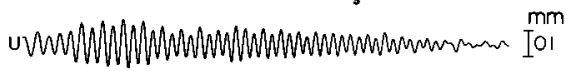

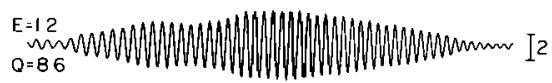

$$
\begin{aligned}
& \text { (b) } \\
& \text { Central Chle, May 10, } 1975 \quad M_{\mathrm{s}}=78 \quad \Delta=82^{\circ}
\end{aligned}
$$

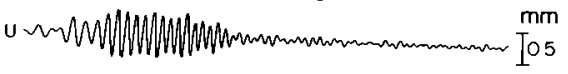

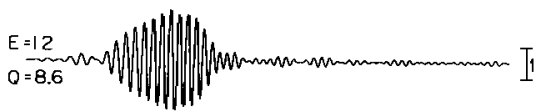

Fig. 8. Surface wave ground motions and the response of the Milne seismograph. (a) New Hebrides Islands earthquake of December 28, 1973. (b) Central Chile earthquake of May 10, 1975. 
state takes place in 1 magnitude unit, or a factor of 10 increase in the amplitude [see Cloud and Hudson, 1961, Figure 4]. The $M_{s}$ (real surface wave magnitude) versus $M_{s}^{*}$ (surface wave magnitude determined from Milne seismograms with $G=5$ ) relation we thus assumed is shown by the solid line in Figure 2. Actually, changing the upper bound in the magnitude from 8.4 to 9 does not substantially affect the $M_{s}$ versus $M_{s}^{*}$ as shown by the dashed lines in Figure 2.

TABLE 4. List of Great Shallow Earthquakes 1897-1903

\begin{tabular}{|c|c|c|c|c|c|c|c|}
\hline Earthquake & Date & $\begin{array}{l}\text { Time, } \\
\text { GMT }\end{array}$ & Epicenter & $Q$ & $M_{s}^{*}$ & $M_{s}$ & Region \\
\hline \multicolumn{8}{|c|}{1897} \\
\hline 1 & Feb. 7 & 7.6 & $40^{\circ} \mathrm{N}, 140^{\circ} \mathrm{E}$ & C & $(7.8)$ & (7.8) & Japan \\
\hline 2 & Feb. 19 & 20.8 & $38^{\circ} \mathrm{N}, 142^{\circ} \mathrm{E}$ & C & $(>7.5)$ & $(>7.5)$ & Japan \\
\hline 3 & Feb. 19 & 23.8 & $38^{\circ} \mathrm{N}, 142^{\circ} \mathrm{E}$ & C & $\ldots$ & $\ldots$ & Japan \\
\hline 4 & May 13 & 12.5 & $12^{\circ} \mathrm{N}, 124^{\circ} \mathrm{E}$ & D & $(7.7)$ & (7.7) & Philippine Islands \\
\hline 5 & June 12 & 11.1 & $26^{\circ} \mathrm{N}, 91^{\circ} \mathrm{E}$ & $\mathbf{A}$ & $(>8.4)$ & $(>8.2)$ & India \\
\hline 6 & Aug. 5 & 0.2 & $38^{\circ} \mathrm{N}, 143^{\circ} \mathrm{E}$ & C & $(>8.2)$ & $(>8.1)$ & Japan \\
\hline 7 & Aug. 15 & $12.3 \pm$ & $18^{\circ} \mathrm{N}, 120^{\circ} \mathrm{E}$ & D & $\ldots$ & $\cdots$ & Philippine Islands \\
\hline 8 & Aug. 16 & 7.9 & $39^{\circ} \mathrm{N}, 143^{\circ} \mathrm{E}$ & $\mathrm{C}$ & $(7.7)$ & (7.7) & Japan \\
\hline 9 & Sep. 20 & 19.1 & $6^{\circ} \mathrm{N}, 122^{\circ} \mathrm{E}$ & D & $(>8.2)$ & $(>8.1)$ & Philippine Islands \\
\hline 10 & Sept. 21 & 5.2 & $6^{\circ} \mathrm{N}, 122^{\circ} \mathrm{E}$ & D & $(>8.2)$ & $(>8.1)$ & Philippine Islands \\
\hline 11 & Oct. 18 & 23.8 & $12^{\circ} \mathrm{N}, 126^{\circ} \mathrm{E}$ & D & (8.1) & $(8.0)$ & Philippine Islands \\
\hline 12 & Oct. 20 & 14.4 & $12^{\circ} \mathrm{N}, 126^{\circ} \mathrm{E}$ & D & (8.0) & (7.9) & Philippine Islands \\
\hline \multicolumn{8}{|c|}{1898} \\
\hline 13 & Jan. 24 & $23 \frac{1}{2}$ & $?$ & G & $\therefore$ & $\cdots$ & $?$ \\
\hline 14 & April 22 & 23.6 & $39^{\circ} \mathrm{N}, 142^{\circ} \mathrm{E}$ & C & 7.9 & 7.9 & Japan \\
\hline 15 & April 29 & 16.3 & $12^{\circ} \mathrm{N}, 86^{\circ} \mathrm{W}$ & B & 7.5 & 7.5 & Nicaragua \\
\hline 16 & June 29 & $18.6 \pm$ & $\left(52^{\circ} \mathrm{N}, 172^{\circ} \mathrm{E}\right)$ & $\mathbf{G}$ & 8.1 & 8.0 & Aleutian Islands? \\
\hline 17 & Aug. 31 & $19.9 \pm$ & $\left(26^{\circ} \mathrm{S}, 68 \frac{1}{2}^{\circ} \mathrm{E}\right)$ & $\mathbf{G}$ & 7.8 & 7.8 & Indian Ocean? \\
\hline 18 & Nov. 17 & $12.8 \pm$ & $\left(16 \frac{1}{2}^{\circ} \mathrm{S}, 168 \frac{1}{2}^{\circ} \mathrm{E}\right)$ & $\mathbf{G}$ & 7.6 & 7.6 & SW Pacific? \\
\hline \multicolumn{8}{|c|}{1899} \\
\hline 19 & Jan. 24 & $2343 \pm$ & $17^{\circ} \mathrm{N}, 98^{\circ} \mathrm{W}$ & D & 8.0 & 7.9 & Mexico \\
\hline 20 & June 14 & $1109 \pm$ & $18^{\circ} \mathrm{N}, 77^{\circ} \mathrm{W}$ & $\mathrm{E}$ & 7.8 & 7.8 & Jamaica \\
\hline 21 & July 14 & $1332 ?$ & $\left(60^{\circ} \mathrm{N}, 150^{\circ} \mathrm{W}\right)$ & $\mathbf{G}$ & 7.7 & 7.7 & Arctic near Alaska \\
\hline 22 & Aug. 24 & $1509 \pm$ & $\left(27^{\circ} \mathrm{S}, 165^{\circ} \mathrm{E}\right)$ & $\mathbf{G}$ & $\cdots$ & $\cdots$ & SW Pacific \\
\hline 23 & Sept. 4 & 0022 & $60^{\circ} \mathrm{N}, 142^{\circ} \mathrm{W}$ & $\mathbf{B}$ & 8.4 & 8.2 & Alaska \\
\hline 24 & Sept. 10 & 1704 & $60^{\circ} \mathrm{N}, 140^{\circ} \mathrm{W}$ & B & 7.8 & 7.8 & Alaska \\
\hline 25 & Sept. 10 & 2141 & $60^{\circ} \mathrm{N}, 140^{\circ} \mathrm{W}$ & $\mathbf{A}$ & 8.4 & 8.2 & Alaska \\
\hline 26 & Sept. 29 & 1703 & $3^{\circ} \mathrm{S}, 128 \frac{1}{2}^{\circ} \mathrm{E}$ & $\mathbf{A}$ & 7.6 & 7.6 & Ceram \\
\hline 27 & Nov. 23 & 0949土 & $53^{\circ} \mathrm{N}, 159^{\circ} \mathrm{E}$ & $\mathbf{E}$ & 7.9 & 7.9 & Kamchatka \\
\hline 28 & Nov. 24 & 1842 & $32^{\circ} \mathrm{N}, 131^{\circ} \mathrm{E}$ & $\bar{B}$ & 7.7 & 7.7 & Japan \\
\hline 29 & Nov. 24 & 1855 & $32^{\circ} \mathrm{N}, 131^{\circ} \mathrm{E}$ & B & $\cdots$ & $\cdots$ & Japan \\
\hline \multicolumn{8}{|c|}{1900} \\
\hline 30 & Jan. 11 & 0907 & $\left(5^{\circ} \mathrm{S}, 148^{\circ} \mathrm{E}\right)$ & $\mathbf{G}$ & 7.5 & 7.5 & SW Pacific? \\
\hline 31 & Jan. 20 & $0633 \frac{1}{2}$ & $20^{\circ} \mathrm{N}, 105^{\circ} \mathrm{W}$ & $\mathrm{C}$ & 7.9 & 7.9 & Mexico \\
\hline 32 & May 16 & $2012^{2}$ & $20^{\circ} \mathrm{N}, 105^{\circ} \mathrm{W}$ & $\mathbf{D}$ & 7.4 & 7.4 & Mexico \\
\hline 33 & June 21 & 2052 & $20^{\circ} \mathrm{N}, 80^{\circ} \mathrm{W}$ & $\mathbf{F}$ & 7.7 & 7.7 & Caribbean? \\
\hline 34 & July 29 & 0659 & $10^{\circ} \mathrm{S}, 165^{\circ} \mathrm{E}$ & $\mathbf{F}$ & 8.1 & 8.0 & New Hebrides? \\
\hline 35 & Oct. 7 & 2104 & $4^{\circ} \mathrm{S}, 140^{\circ} \mathrm{E}$ & $\mathbf{F}$ & 7.4 & 7.4 & New Guinea? \\
\hline 36 & Oct. 9 & 1228 & $60^{\circ} \mathrm{N}, 142^{\circ} \mathrm{W}$ & $\mathrm{C}$ & 8.2 & 8.1 & Alaska \\
\hline 37 & Oct. 29 & 0911 & $11^{\circ} \mathrm{N}, 66^{\circ} \mathrm{W}$ & B & 8.2 & 8.1 & Venezuela \\
\hline 38 & Dec. 25 & 0504 & $43^{\circ} \mathrm{N}, 146^{\circ} \mathrm{E}$ & $\mathbf{C}$ & 7.6 & 7.6 & Japan \\
\hline \multicolumn{8}{|c|}{1901} \\
\hline 39 & Jan. 7 & $0029 \frac{1}{2}$ & $2^{\circ} \mathrm{S}, 82^{\circ} \mathrm{W}$ & $\mathbf{E}$ & 7.7 & 7.7 & Ecuador \\
\hline 40 & April 5 & $2330 \frac{2}{4}$ & $45^{\circ} \mathrm{N}, 148^{\circ} \mathrm{E}$ & $\mathbf{C}$ & 7.9 & 7.9 & South Kurile Islands \\
\hline 41 & June 24 & $0702 \frac{1}{2}$ & $27^{\circ} \mathrm{N}, 130^{\circ} \mathrm{E}$ & $\mathbf{E}$ & 7.7 & 7.7 & Ryukyu Islands \\
\hline 42 & Aug. 9 & 0923.5 & $40^{\circ} \mathrm{N}, 144^{\circ} \mathrm{E}$ & $\mathbf{C}$ & 7.8 & 7.8 & Japan \\
\hline 43 & Aug. 9 & 1301 & $22^{\circ} \mathrm{S}, 170^{\circ} \mathrm{E}$ & $\mathbf{E}$ & 8.4 & 8.2 & New Hebrides? \\
\hline 44 & Aug. 9 & $1833 \frac{3}{4}$ & $40^{\circ} \mathrm{N}, 144^{\circ} \mathrm{E}$ & $\mathrm{C}$ & 8.0 & 7.9 & Japan \\
\hline 45 & Dec. 14 & $2257 \frac{1}{4}$ & $14^{\circ} \mathrm{N}, 122^{\circ} \mathrm{E}$ & $\mathbf{D}$ & 7.5 & 7.5 & Philippine Islands \\
\hline 46 & Dec. 31 & $0902 \frac{1}{2}$ & $52^{\circ} \mathrm{N}, 177^{\circ} \mathrm{W}$ & $\mathbf{D}$ & 7.5 & 7.5 & Aleutian Islands \\
\hline \multicolumn{8}{|c|}{1902} \\
\hline 47 & Jan. 1 & $0520 \frac{1}{2}$ & $55^{\circ} \mathrm{N}, 165^{\circ} \mathrm{W}$ & $\mathbf{D}$ & 7.5 & 7.5 & off Alaska? \\
\hline 48 & Jan. 24 & $2327^{2}$ & $8^{\circ} \mathrm{S}, 150^{\circ} \mathrm{E}$ & $\mathbf{D}$ & 7.7 & 7.7 & Bismarck Islands \\
\hline 49 & Feb. 9 & $0735 \frac{1}{2}$ & $20^{\circ} \mathrm{S}, 174^{\circ} \mathrm{W}$ & D & 7.4 & 7.4 & Tonga Islands \\
\hline 50 & April 19 & $0223 \frac{1}{2}$ & $14^{\circ} \mathrm{N}, 91^{\circ} \mathrm{W}$ & C & 8.0 & 7.9 & Guatemala \\
\hline 51 & Aug. 22 & 0300 & $40^{\circ} \mathrm{N}, 77^{\circ} \mathrm{E}$ & B & 8.2 & 8.2 & Turkestan \\
\hline 52 & Sept. 22 & $0146 \frac{1}{2}$ & $18^{\circ} \mathrm{N}, 146^{\circ} \mathrm{E}$ & $\mathrm{C}$ & 8.0 & 7.9 & Marianne Islands \\
\hline 53 & Sept. 23 & $2018 \frac{1}{4}$ & $16^{\circ} \mathrm{N}, 93^{\circ} \mathrm{W}$ & C & 8.2 & 8.2 & off south Mexico \\
\hline 54 & Dec. 12 & $2310 \pm$ & $29^{\circ} \mathrm{N}, 114^{\circ} \mathrm{W}$ & $\mathbf{E}$ & 7.6 & 7.6 & Gulf of Califormia \\
\hline
\end{tabular}


TABLE 4. (continued)

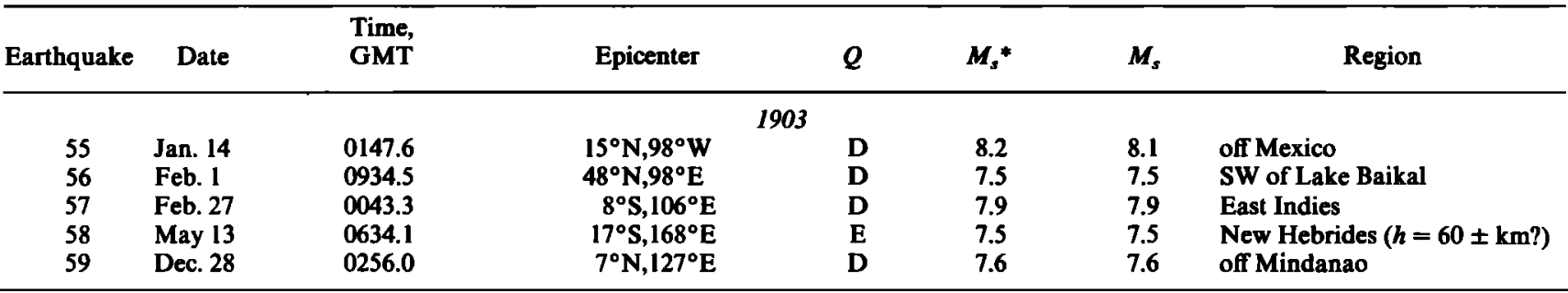

This table lists all of the 59 events listed by Gutenberg [1956a, Table 3]. Epicenter. Gutenberg's determination. Gutenberg assumed the epicenters of 16, 17, and 18 on the basis of seismicity. Gutenberg used the location noted by Milne for the epicenters of 21, 22, and 30. $Q$ : quality of location. See Gutenberg [1956a]. $M_{s}^{*}$ : surface wave magnitudes determined with the assumption that the magnification is 5 . Parentheses indicate that $M_{s}^{*}$ was determined only from one or two station data. $M_{s}^{*}=\log A_{\max }+1.656 \log \Delta+1.818$. $M_{s}$ : corrected surface wave magnitude. The average number of stations used in the calculation of $M_{s}^{*}$ is 2 (1897), 4 (1898), 17 (1899), 9 (1900), 13 (1901), 14 (1902), and 15 (1903). For the origin times of 49 and 53, minor corrections were made on the basis of the original work sheets.

\section{Surface Wave Magnitude of The Events FROM 1897 TO 1903}

The amplitude data of Milne seismograms for the events from 1897 to 1903 are listed in Gutenberg's unpublished work sheets for the 1956 paper. We used the publications of the British Association for the Advancement of Science for the period 1897-1903 to check and supplement Gutenberg's notes. Gutenberg [1956a] determined $m$ by using these data (with the assumption of $G=5$ ), and Richter [1958] converted $m$ to $M$ by using the relation $M=1.59 m-3.97$. In order to maintain consistency with the scale used in our calibration, we calculated $M_{s}^{*}$ from the original amplitude data by assuming $G=5$. The results are listed in Table 4. Theoretically, $M_{s}^{*}$ should agree with $M$, but our calculations showed that $M$ is consistently larger than $M_{s}^{*}$. This difference is due to the fact that Gutenberg [1956a] always rounded off the hundredths digit and raised the tenths digit by $I$ (for example, 7.82 to 7.9). Also, small roundoff errors resulted from conversion of $\boldsymbol{m}$ to $\boldsymbol{M}$.

For many events in 1897 , only one or two stations were available for the magnitude determination. The results for these events are very unreliable and are in the parentheses in Table 4. Apparently, Gutenberg [1956a] assigned the magnitude to these events on his own judgments. The average number of stations used for the calculation of $M_{s}^{*}$ in Table 4 is as follows: 2 (1897), 4 (1898), 7 (1899), 9 (1900), 13 (1901), 14 (1902), and 15 (1903). Since only 2 and 4 stations are used for 1897 and 1898, respectively, the results for these two years are less reliable. The station data for the larger earthquakes are listed in Table A-4 (see also Table A-2) (microfiche appendix).

If many stations went off scale, the measurement of $M_{s}^{*}$ is meaningless. However, as shown in Table A-4, most of the stations were on scale for the events from 1897 to 1903 . Only for two events, the 1902 Turkestan event and the 1902 event off south Mexico, four or more stations were off scale. We therefore consider that most of the $M_{s}^{*}$ measurements in Table 4 are meaningful.

We then converted $M_{s}^{*}$ to $M_{s}$ by using the relation given by the solid line in Figure 2. This $M_{s}$ scale can be considered to be identical to that defined originally by Gutenberg [1945]. Table 4 lists $M_{s}$ thus obtained for the period from 1897 to 1903. For the two events, the 1902 Turkestan event and the 1902 event off south Mexico, the present calibration is not meaningful because of the saturation of the records. We substituted the value of $M_{s}^{*}$ for $M_{s}$ for these events. A small number of records obtained by Nicolajew instruments were also used in Gutenberg's [1956a] study. However, since the deter- minations of the magnitudes with the records of the Nicolajew instruments were very few, we paid no particular consideration to those data in this study.

Recently, Thatcher and Plafker [1977] determined the magnitudes of three Yakutat Bay, Alaska, earthquakes in 1899 and 1900 by using a small number of early damped seismographic records. They obtained 8.4 and 8.1 for the September 10,1899, event and the October 9, 1900, event, respectively, which compare reasonably well with the values listed in Table 4, 8.2 and 8.1, respectively. However, for the event on September 4, 1899, Thatcher and Plafker [1977] obtained 8.5, which is significantly larger than our value, 8.2. The cause of this discrepancy is presently unknown.

From Table 4 the annual number of events with $M_{s} \geq 8$ was obtained and plotted in Figure 1. If we ignore the unreliable result for 1897 , the peak around the turn of the century no longer exists. The peak in 1906 consists of the January 31 Colombia earthquake $\left(M_{s}=8.7\right)$, the April 18 San Francisco earthquake $\left(M_{s}=8.3\right)$, the August 17 Aleutian Islands earthquake $\left(M_{s}=8.2\right)$, the August 17 Chilean earthquake $\left(M_{s}=\right.$ 8.4), and the September $14 \mathrm{New}$ Britain Islands earthquake $\left(M_{s}=8.1\right)$.

While studying Gutenberg's original work sheets for the 1956 paper, we found additional data for 49 events, some of which were mentioned in the 1956 paper. We determined $M_{s}$ for these events by using the method described above. The results are listed in Table 5. The amplitude and magnitude data for major earthquakes listed in this table are given in Table A5 (see also Table A-2, microfiche appendix). As mentioned earlier, the results for the 1896 and 1897 events are very uncertain.

\section{CONCLUSION}

Because of saturation of the Milne seismograms for very large events used by Gutenberg [1956a] for calibration, we suspect that the gain $(=5)$ used by Gutenberg [1956a] is underestimated and therefore the magnitude overestimated. Our experiments using a newly constructed Milne seismograph as well as the numerical experiments using observed surface waves suggest that the effective gain can be as large as 20 . Because of the unknown damping characteristics of the original Milne seismograph, we could not make definitive calibration of the instrument. However, it is almost certain from Figure 2 that the magnitudes of earthquakes larger than $M_{s}=7.7$ listed by Gutenberg [1956a] were considerably overestimated, in the extreme case by as much as $0.6(=\log (20 / 5))$. Assuming that the correction increases linearly from 0 to 0.6 as $M_{s}$ increases from 7.7 to 8.7 , we corrected $M_{s}^{*}$ (surface wave magnitude 
TABLE 5. List of Large Shallow Earthquakes 1896-1903

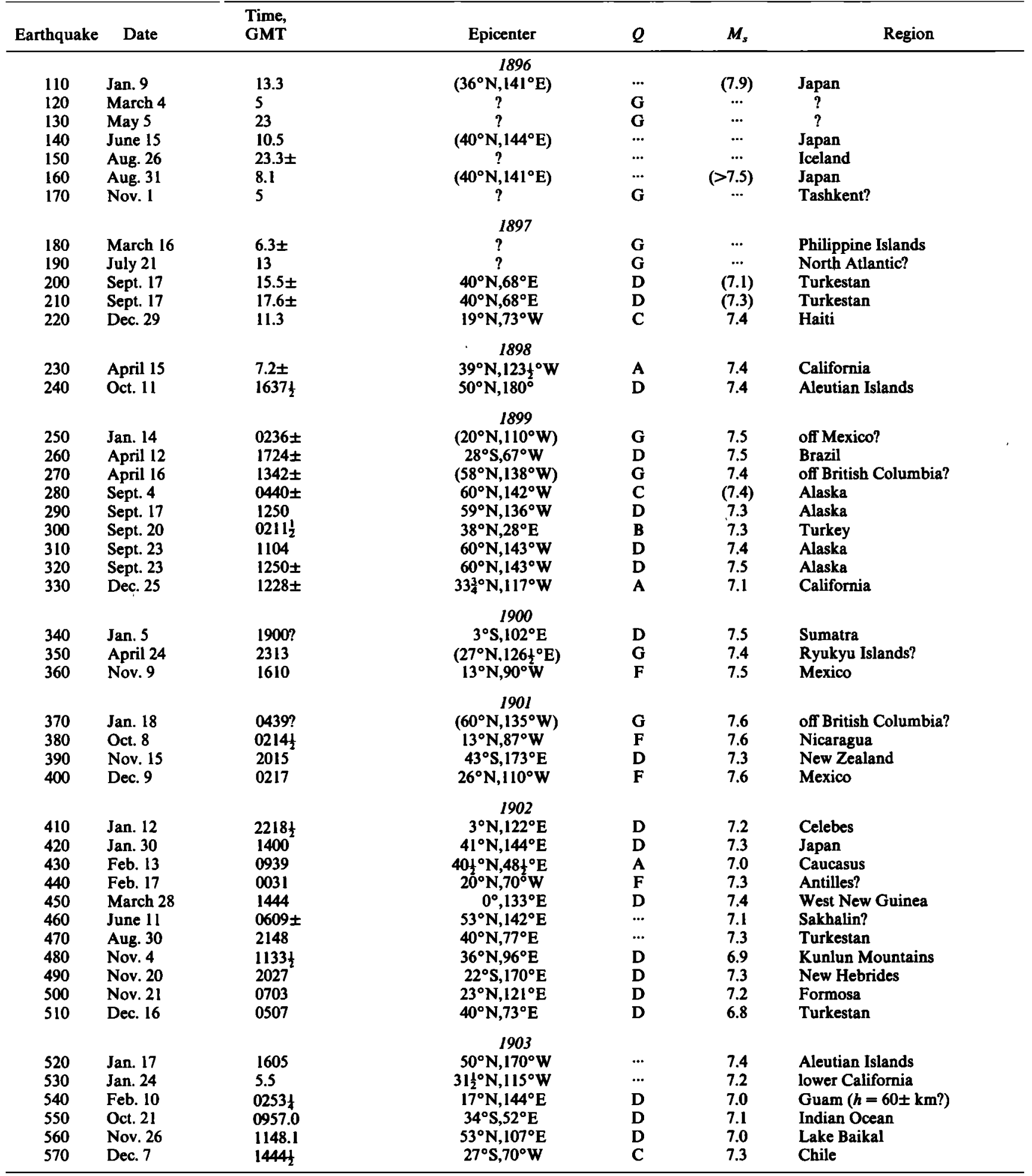

The epicenters of 110;140, and 160 were taken from the Tokyo Astronomical Observatory [1975]. For 250, 270, 350, and 370, Gutenberg used the epicenters given by Milne, only for calculating epicentral distances. For other column heads, see footnote for Table 4.

obtained with the assumption that $G=5$ ) to obtain $M_{s}$. Thus the values of $M_{s}^{*}$ in Table 4 may be considered the upper limit of the surface wave magnitude. Although we believe that the values of $M_{s}$ listed in Table 4 are the best estimates we can make under various considerations, they are still subject to some uncertainty due to the rather erratic response and the limited dynamic range of the Milne seismograph.
Nevertheless, the suggested reductions in the magnitude are systematic and large enough to indicate that the turn-of-thecentury peak, if it exists, is of marginal significance. A recent study by $A b e$ [1979] shows that the activity of tsunamigenic earthquakes during this period is not higher than that during any other periods. Abe's result is consistent with the present conclusion. 
Acknowledgments. We thank N. Ambraseys of the Imperial College of Science and Technology, London, England; A. McConnell of the Science Museum, London, England; and T. Usami of the Earthquake Research Institute, Tokyo University, for providing us with valuable information regarding the original Milne seismograph. We thank Karen McNally for reviewing the manuscript. We thank David Hadley for providing us with the digitized seismograms used for the numerical experiments. Francis Lehner and the technical staff of the Seismological Laboratory of the California Institute of Technology designed and operated the Pasadena Milne seismograph. This research was supported by the National Science Foundation under grant EAR77-1364l. Contribution 3179, Division of Geological and Planetary Sciences, California Institute of Technology, Pasadena, California 91125.

\section{REFERENCES}

Abe, K., Size of great earthquakes of 1837-1974 inferred from tsunami data, J. Geophys. Res., 84, 1561-1568, 1979.

Abe, $\mathbf{K}$., and $\mathbf{H}$. Kanamori, Magnitudes of great shallow earthquakes from 1953 to 1977, Tectonophysics, 60, in press, 1979.

Cloud, W. K., and D. E. Hudson, A simplified instrument for recording strong motion earthquakes, Bull. Seismol. Soc. Amer., 51, 159$174,1961$.

Geller, R. J., and H. Kanamori, Magnitude of great shallow earthquakes from 1904 to 1952, Bull. Seism. Soc. Amer., 67, 587-598, 1977.

Gutenberg, B., Amplitudes of surface waves and magnitudes of shallow earthquakes, Bull. Seism. Soc. Amer., 35, 3-12, 1945.
Gutenberg, B., Great earthquakes 1896-1903, Eos Trans. $A G U, 37$, 608-614, 1956a.

Gutenberg, B., The energy of earthquakes, Quart. J. Geol. Soc. London, $112,1-14,1956 b$.

Gutenberg, B., and C. F. Richter, Seismicity of the Earth, 2nd ed., 310 pp., Princeton University Press, Princeton, N. J., 1954.

Kanamori, H., The energy release in great earthquakes, J. Geophys. Res., 82, 2981-2987, 1977.

Knott, C. G., The Physics of Earthquake Phenomena, 283 pp., Oxford at the Clarendon Press, London, 1908.

Munro, R. W., The Seismograph, 15 pp., 103 Cornwall Road, South Tottenham, London, 1908.

Reid, H. F., On the choice of a seismograph, Bull. Seismol. Soc. Amer., 2, 8-30, 1912.

Richter, C. F., Elementary Seismology, 708 pp., W. H. Freeman, San Francisco, Calif., 1958.

Thatcher, W., and G. Plafker, The 1899 Yakutat bay, Alaska earthquakes: Seismograms and crustal deformation, paper presented at the Seismological Society of America meeting, Sacramento, Calif., 1977.

Tokyo Astronomical Observatory, Science Almanac, Maruzen, Tokyo, 1975.

Walker, G. W., Modern Seismology, 88 pp., Longmans, Green, London, 1913.

(Received November 14, 1978; revised April 11, 1979; accepted May 18, 1979.) 